\title{
Pilot trial of Melissa officinalis L. leaf extract in the treatment of volunteers suffering from mild-to-moderate anxiety disorders and sleep disturbances
}

\author{
Julien Cases $\cdot$ Alvin Ibarra $\cdot$ Nicolas Feuillère • \\ Marc Roller · Samir G. Sukkar
}

Received: 23 November 2010/Accepted: 2 December 2010/Published online: 17 December 2010

(C) The Author(s) 2010. This article is published with open access at Springerlink.com

\begin{abstract}
Botanicals are an alternative option to prescription drugs for the alleviation of symptoms due to anxiety disorders and insomnia. Melissa officinalis L. has been shown as an anti-stress and anxiolytic agent. We previously reported moderate stress improvement in mice in which Cyracos ${ }^{\circledR}$, a standardized Melissa officinalis L. extract, was administrated. Cyracos ${ }^{\circledR}$ contains phytochemicals that inhibit gamma-aminobutyric acid catabolism. This was a prospective, open-label, 15-day study to evaluate the efficacy of Cyracos ${ }^{\circledR}$ on stressed volunteers, who have mild-to-moderate anxiety disorders and sleep disturbances. Using clinician rating criteria, primary outcomes showed improvement of symptoms. Cyracos ${ }^{\circledR}$ reduced anxiety manifestations by $18 \%(p<0.01)$, ameliorated anxiety-associated symptoms by $15 \%(p<0.01)$ and lowered insomnia by $42 \%(p<0.01)$. As much as $95 \%$ of subjects $(19 / 20)$ responded to treatment, of which $70 \%$ $(14 / 20)$ achieved full remission for anxiety, $85 \%$ (17/20) for insomnia, and 70\% (14/20) for both. Our study demonstrates, for the first time that chronic administration of Melissa officinalis L. relieves stress-related effects. It is critical that further studies incorporate a placebo and investigate physiological stress markers.
\end{abstract}

J. Cases $\cdot$ N. Feuillère $\cdot$ M. Roller

Naturex SA, BP 1218, 84911 Avignon, France

A. Ibarra $(\bowtie)$

Naturex Inc., 375 Huyler Street, South Hackensack, NJ 07606, USA

e-mail: a.ibarra@naturex.us

S. G. Sukkar

Dietetics and Clinical Nutrition Unit,

San Martino University Hospital, Largo Rosanna Benzi 10, 16132 Genoa, Italy
Keywords Melissa officinalis L. A Anxiety - Insomnia · Free Rating Scale for Anxiety (FRSA) · Hamilton Rating Scale for Depression (HRSD) · Gamma-aminobutyric acid (GABA)

\section{Introduction}

Anxiety comprises behavioral, cognitive and physiological responses to threatening situations or uncertainty, and is defined as an unpleasant emotional state for which the cause is not readily identifiable or perceived to be uncontrollable or unavoidable [1]. Anxiety often manifests as debilitating chronic conditions, which can develop at an early age or appear suddenly after a triggering event. Such conditions are prone to flare-up at times of high stress and are frequently accompanied by physiological and psychological symptoms, including somatic (e.g., headache, sweating, muscle spasms, palpitations, and hypertension) and psychosomatic (e.g., mental confusion, compulsory obsessive behaviors and emotional instability) changes, which, in certain cases, lead to fatigue and exhaustion [2].

Stress represents an interaction between an environmental stimulus (stressor) and a stress response system, such as the hypothalamic-pituitary-adrenal (HPA) axis and catecholamines [1]. Individuals who are exposed to stressful conditions exhibit autonomic responses, such as changes in heart rate and body temperature, in addition to behavioral responses that are related to elevated anxiety and endocrine responses [3]. Consequently, anxiety can constitute a component of a potential stressor [1].

Activation of the stress system induces insomnia. Moreover, when insomnia is chronic and severe, it develops into a stressor [4]. Insomnia is a heterogeneous disorder that entails difficulties with sleep onset, maintenance and early 
morning wakening [5]. Subjective complaints of decreased duration of sleep or diminished sleep quality, depth and efficiency are also typical definitions of insomnia [6].

A myriad of evidence indicates that drug medications that are often used to treat anxiety and insomnia result in adverse effects that are related to acquired tolerance and withdrawal from the drug [7,8]. Botanical treatments that have been developed as alternatives are known to induce calming effects $[8,9]$. Consequently, traditional botanical extracts (e.g., valerian, lime blossoms, passiflora, and lemon balm) have been developed commercially, because their efficacy is rarely linked to side effects [10-12]. Thus, a botanical extract that treats anxiety should certainly be a component of the treatment regimen for anxiety-induced disorders and sleep disturbance. These properties exist in a Melissa officinalis L. (lemon balm) leaf extract that has been standardized to contain more than 5\% hydroxycinnamic acid content [13].

Melissa officinalis L. improves cognitive performance and mood [14, 15], reduces induced stress [16] and has anxiolytic effects [17] in humans. These studies, however, were conducted using acute treatment with the botanical, and to date there are no published clinical trials of Melissa officinalis L. extract for the treatment of chronic manifestations. Recently, we reported novel anxiolyticlike effects under moderate stress-induced conditions in mice that were administered Cyracos ${ }^{\circledR}$ chronically for 15 days [18]. Cyracos ${ }^{\circledR}$ contains rosmarinic acid and the pentacyclic triterpenoids, ursolic and oleanolic acids [18], which inhibit gamma-aminobutyric acid (GABA) catabolism $[19,20]$. Due to its efficacy in improving anxiety under moderate stress, $\mathrm{Cyracos}^{\circledR}$ may be a valuable alternative to pharmaceutical drugs in treating anxiety disorders.

Although the open-label design is unable to rule out placebo effects from those of Cyracos ${ }^{\circledR}$, this pilot study was aimed to estimate the improvement of symptoms in the treatment of stressed volunteers, who are affected with mild-to-moderate anxiety disorders and sleep disturbances, but are otherwise healthy.

\section{Materials and methods}

Volunteers

Participants were recruited through advertisements and from the outpatient Dietetics and Clinical Nutrition Unit of San Martino University Hospital, Genoa, Italy. Volunteers who met DSM-IV-TR criteria [21] for a primary diagnosis of anxiety disorders and sleep disturbances were eligible.
Volunteers who met at least one exclusion criterion were not enrolled into the trial. Exclusion criteria included: pregnancy, lactation, intention to become pregnant during the course of the study or volunteers of child-bearing potential not using adequate contraception; consumption of anti-anxiety drugs, antidepressants, hypnoinducers or sedatives 10 days before the start of the study; diabetes; asthma; hypo- and hyperthyroidism; depression; severe obsessive-compulsive disturbances; schizophrenia; psychosis in general; consumption of serotonin-reuptake inhibitors drugs.

\section{Design}

Institutional review board approval was obtained as well as written informed consent from all volunteers prior to initiation of the study. The trial was conducted in accordance with the Declaration of Helsinki, Good Clinical Practice guidelines and the Italian drug law.

A prospective, single-center, open-label study was conducted on 20 stressed volunteers (outpatients; 6 male, 14 female) between the ages of 18 and 70 years, who were affected by mild-to-moderate anxiety disorders and sleep disturbances, but were otherwise healthy. All volunteers were treated with Cyracos $^{\circledR}$.

\section{Treatment}

\section{$\operatorname{Cyracos}^{\circledR}$}

Cyracos $^{\circledR}$ (Naturex, SA, France) is a hydroalcoholic Melissa officinalis L. leaf extract that has been standardized to consist of more than $7 \%$ rosmarinic acid and greater than $15 \%$ hydroxycinnamic acid derivatives [18].

Table 1 summarizes the content of the principal phytochemical compounds in Cyracos ${ }^{\circledR}$ compared with Melissa officinalis L. leaves and extracts, as published. The values for Cyracos ${ }^{\circledR}$ were derived from five industrial batches [mean \pm standard error of the mean (SEM)], manufactured at Naturex SA, Site d'Agroparc BP 1218-84911 Avignon, France. Samples of Cyracos ${ }^{\circledR}$ were also analyzed with regard to their hydroxycinnamic acid [18], flavonoid [22] and triterpene pentacyclic acid [18] content.

\section{Cyracos $^{\circledR}$ administration}

Each volunteer took $600 \mathrm{mg}$ of $\mathrm{Cyracos}{ }^{\circledR}$ per day, divided into two doses: one tablet in the morning and another in the evening before falling asleep. Each tablet contained $66.67 \%$ Cyracos $^{\circledR}$ (300 mg), 18.89\% maltodextrin, $11.11 \%$ microcrystalline cellulose, $1.56 \%$ stearate magnesium, $1.11 \%$ talc and $0.66 \%$ micronized silica. 
Table 1 Chief phytochemicals in $\operatorname{Cyracos}^{\circledR}$ (mean \pm SEM of five industrial batches) and Melissa officialis L. leaves and extracts, as reported in literature

${ }^{\mathrm{a}}[38],{ }^{\mathrm{b}}[39],{ }^{\mathrm{c}}[40],{ }^{\mathrm{d}}[41],{ }^{\mathrm{e}}[22]$, f $[42],{ }^{\mathrm{g}}[43],{ }^{\mathrm{h}}[44],{ }^{\mathrm{i}}[45]$

\section{Medical interviews}

\section{Primary outcomes for anxiety disorders and insomnia}

Volunteers were interviewed using a test that was based on the Free Rating Scale for Anxiety (FRSA) to evaluate anxiety and its associated symptoms [23] and on the Hamilton Rating Scale for Depression (HRSD) to assess insomnia [24] at baseline (pre-administration) and at the end of the study (post-administration) to evaluate the overall clinical change in symptoms. The 20-question test was divided into three categories: anxiety manifestations, anxiety-associated symptoms and insomnia. Insomnia was further categorized into initial, middle and delayed. Table 2 shows the scales and definitions that were used for each test category.

The Clinical Global Impression-Improvement scale (CGI-I) was used to measure volunteers' overall clinical improvement in anxiety disorders and sleep disturbances over the 15-day treatment trial. The CGI-I consists of a clinical rating of a patient's overall improvement in symptoms as compared to baseline, with scores ranging from 1 ("very much improved") to 7 ("very much worse") [25]. Treatment responders were defined as those volunteers whose GI endpoint score was $\leq 2$ ("much" or "very much improved").

$$
\operatorname{Cyracos}^{\circledR}, \%
$$

Melissa officinalis L.

Leaves $\quad$ Extracts, \%

(fresh and dried), \%

$\begin{array}{rll}7.95 \pm 0.29 & 0.52-4.60^{\mathrm{a}, \mathrm{b}, \mathrm{c}, \mathrm{d}} & 2.21-9.65^{\mathrm{b}, \mathrm{e}, \mathrm{f}} \\ 18.50 \pm 0.63 & 11.29^{\mathrm{e}} & 7.01-12.51^{\mathrm{b}, \mathrm{e}, \mathrm{f}} \\ & & \\ 0.23 \pm 0.01 & - & 0.93^{\mathrm{e}} \\ 0.46 \pm 0.04 & 0.54^{\mathrm{b}} & 0.18-0.51^{\mathrm{b}, \mathrm{f}} \\ 0.69 \pm 0.04 & 0.45-1^{\mathrm{e}, \mathrm{g}} & 0.23^{\mathrm{f}} \\ & & \\ 0.22 \pm 0.03 & 0.06-0.45^{\mathrm{h}, \mathrm{i}} & - \\ 0.64 \pm 0.09 & 0.21-0.58^{\mathrm{i}} & -\end{array}$

Safety

Adverse events were evaluated at each study visit by directly asking volunteers if they experienced any adverse events or illness.

Statistical analysis

All values were expressed as mean $(\mathrm{M}) \pm$ standard error to the mean (SEM). Statistical analyses were performed using analysis of variance with a nonparametric Wilcoxon rank-sum test, two-tailed and alpha set at 0.001 level (Excel Stat, 2008). Statistical significance was set to $p<0.05$ and $p<0.01$.

\section{Results}

Efficacy and safety

Cyracos $^{\circledR}$ treatment demonstrated a significant improvement in all categories studied: anxiety manifestations, anxiety-associated symptoms and insomnia.

The following results are based on a scale of $0-3$ for anxiety manifestations and anxiety-associated symptoms

Table 2 Scales used in the 20-Question Inventory that is based on the Free Rating Scale for Anxiety (FRSA) to evaluate anxiety and its associated symptoms, and on the Hamilton Rating Scale for Depression (HRSD) to assess insomnia

\begin{tabular}{|c|c|c|c|c|}
\hline \multirow{2}{*}{$\begin{array}{l}\text { Anxiety } \\
\text { manifestations }\end{array}$} & \multirow{2}{*}{$\begin{array}{l}\text { Anxiety-associated } \\
\text { symptoms }\end{array}$} & \multicolumn{3}{|l|}{ Insomnia } \\
\hline & & Initial & Middle & Delayed \\
\hline $0=$ Absent & $0=$ Absent & $0=$ Absent & $0=$ Absent & $0=$ Absent \\
\hline $\begin{array}{l}1=\text { Mild to } \\
\text { moderate }\end{array}$ & $1=$ Mild to moderate & $\begin{array}{l}1=\text { Taking } 35-45 \text { min to fall } \\
\text { asleep }\end{array}$ & $1=$ Restless nights & $\begin{array}{l}1 \text { = Early awakening at } \\
\text { dawn }\end{array}$ \\
\hline $2=$ Moderate & $2=$ Moderate & $\begin{array}{l}2=\text { Always difficulty falling } \\
\text { asleep }\end{array}$ & $\begin{array}{l}2=\text { Wakening during the } \\
\text { night }\end{array}$ & $2=$ Wakening at dawn \\
\hline $3=$ Severe & $3=$ Severe & & & \\
\hline
\end{tabular}


with 3 being the most severe, and on a scale of $0-2$ for insomnia with 2 having maximum severity. Values were obtained before and after the 15-day administration of Cyracos $^{\circledR}$.

Cyracos ${ }^{\circledR}$ was well tolerated by the studied population. No adverse effects were observed and all volunteers complied with the treatment until the end of the study.

Primary outcomes

\section{Anxiety disorders}

Anxiety manifestations Agitation decreased by $35 \%$ $(1.30 \pm 0.16$ vs. $0.25 \pm 0.10, p<0.01)$, hyperactivity by $10 \%(0.40 \pm 0.11$ vs. $0.10 \pm 0.07, p<0.05)$ and tension by $18 \%(0.70 \pm 0.18$ vs. $0.15 \pm 0.08, p<0.01)$. Motor disturbances, however, declined marginally by $10 \%$ (0.45 \pm 0.15 vs. $0.15 \pm 0.08, p<0.08$; see Fig. 1$)$.

Total anxiety manifestations were reduced by $18 \%$ ( $p<0.01$ ), from $0.71 \pm 0.10$ to $0.16 \pm 0.06$, representing an improvement from mild-to-moderate anxiety to the absence of measurable anxiety.

Anxiety-associated symptoms Several parameters of anxiety-associated symptoms were greatly reduced, such as eating problems, which were lowered by $33 \%$ (1.60 \pm 0.22 vs. $0.60 \pm 0.15, p<0.01)$, emotional instability by $7 \%$ $(0.25 \pm 0.12$ vs. $0.05 \pm 0.05, p<0.05)$, fatigue by $18 \%$ $(0.80 \pm 0.20$ vs. $0.25 \pm 0.10, p<0.01)$, feelings of guilt by $15 \%(0.60 \pm 0.20$ vs. $0.15 \pm 0.08, p<0.01)$, feeling of inferiority by $18 \% \quad(0.80 \pm 0.20$ vs. $0.25 \pm 0.10$, $p<0.01)$, intellectual disturbance by $28 \%(1.05 \pm 0.17$

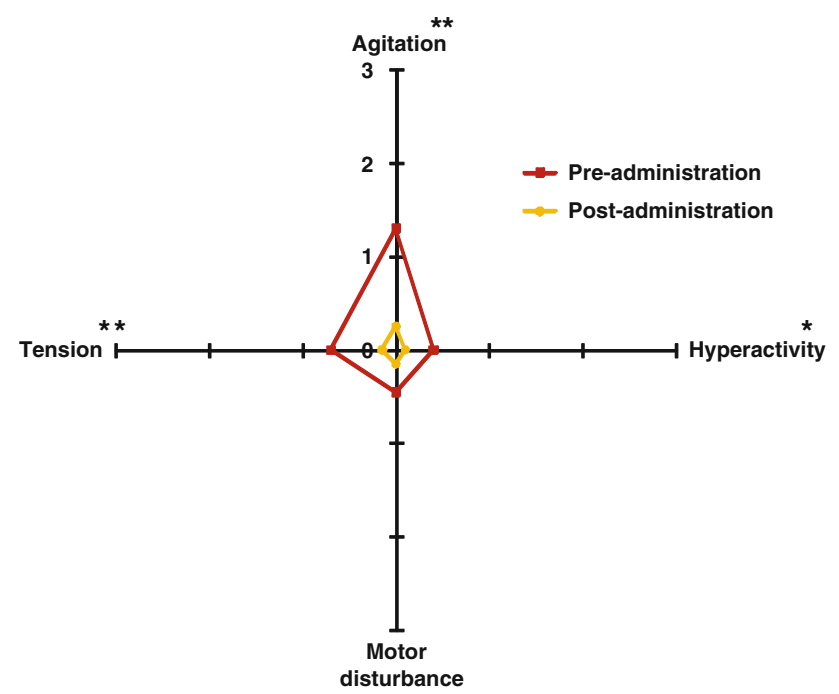

Fig. 1 Anxiety manifestations before and after 15 days of treatment with $600 \mathrm{mg}$ Cyracos $^{\circledR}$ (300 mg twice a day) in 20 volunteers affected by anxiety disorders and sleep disturbances. $* p<0.05$; $* * p<0.01$ vs. $0.20 \pm 0.09, p<0.01)$, muscular reactions by $13 \%$ $(0.50 \pm 0.15$ vs. $0.10 \pm 0.07, p<0.01)$, poor interpersonal relationships by $13 \%(0.65 \pm 0.23$ vs. $0.25 \pm 0.14$, $p<0.01)$ and psychosomatic symptoms by $33 \%(1.05 \pm$ 0.18 vs. $0.05 \pm 0.05, p<0.01)$. To a lesser extent, the following symptoms were reduced: obsessive-compulsive behavior by $5 \%(0.35 \pm 0.18$ vs. $0.20 \pm 0.12, p<0.05)$, speech problems by $3 \%(0.10 \pm 0.07$ vs. $0.00 \pm 0.00$, $p<0.05)$ and vague somatic symptoms by $8 \%(0.50 \pm$ 0.15 vs. $0.25 \pm 0.10, p<0.05)$. Skin reactions were not reported before or after the treatment (see Fig. 2).

In total, anxiety-associated symptoms declined by $15 \%$ $(p<0.01)$, from $0.63 \pm 0.10$ to $0.18 \pm 0.04$, representing an improvement from a mild-to-moderate level of symptoms to their absence.

\section{Insomnia}

All measurements for insomnia were greatly reduced at the end of the study. Initial insomnia decreased by $53 \%$ $(1.55 \pm 0.11$ vs. $0.50 \pm 0.11, p<0.01)$, middle insomnia by $45 \%(1.20 \pm 0.14$ vs. $0.30 \pm 0.11, p<0.01)$ and delayed insomnia by $28 \%(0.65 \pm 0.17$ vs. $0.30 \pm 0.06$, $p<0.01$; see Fig. 3).

In total, insomnia was reduced by $42 \%(p<0.01)$, from $1.13 \pm 0.10$ to $0.30 \pm 0.06$, representing an improvement from difficulty in falling asleep to having minimal to no difficulties.

\section{Clinical rating of improvement}

Based on CGI improvement scores, 19 volunteers out of 20 demonstrated a clinically significant positive treatment response for anxiety disorders; 14 volunteers reached full remission of symptoms; 5 volunteers responded to treatment with significant symptom improvement but not full remission; one patient minimally improved (see Table 3).

For insomnia, 20 volunteers out of 20 demonstrated a clinically significant positive treatment response; 17 volunteers reached full remission of symptoms; 3 volunteers responded to treatment with significant symptom improvement but not full remission (see Table 3).

\section{Discussion}

In this open-label pilot study, based on the rapid rate of response by volunteers to treatment with $\mathrm{Cyracos}^{\circledR}$, there was significant improvement of associated symptoms of anxiety and insomnia.

Anxiety is a psychological and physiological condition that is characterized by cognitive, somatic, emotional and 
Fig. 2 Anxiety-associated symptoms before and after 15 days of treatment with $600 \mathrm{mg} \mathrm{Cyracos}{ }^{\circledR}(300 \mathrm{mg}$ twice a day) in 20 volunteers affected by anxiety disorders and sleep disturbances.

$* p<0.05 ; * * p<0.01$

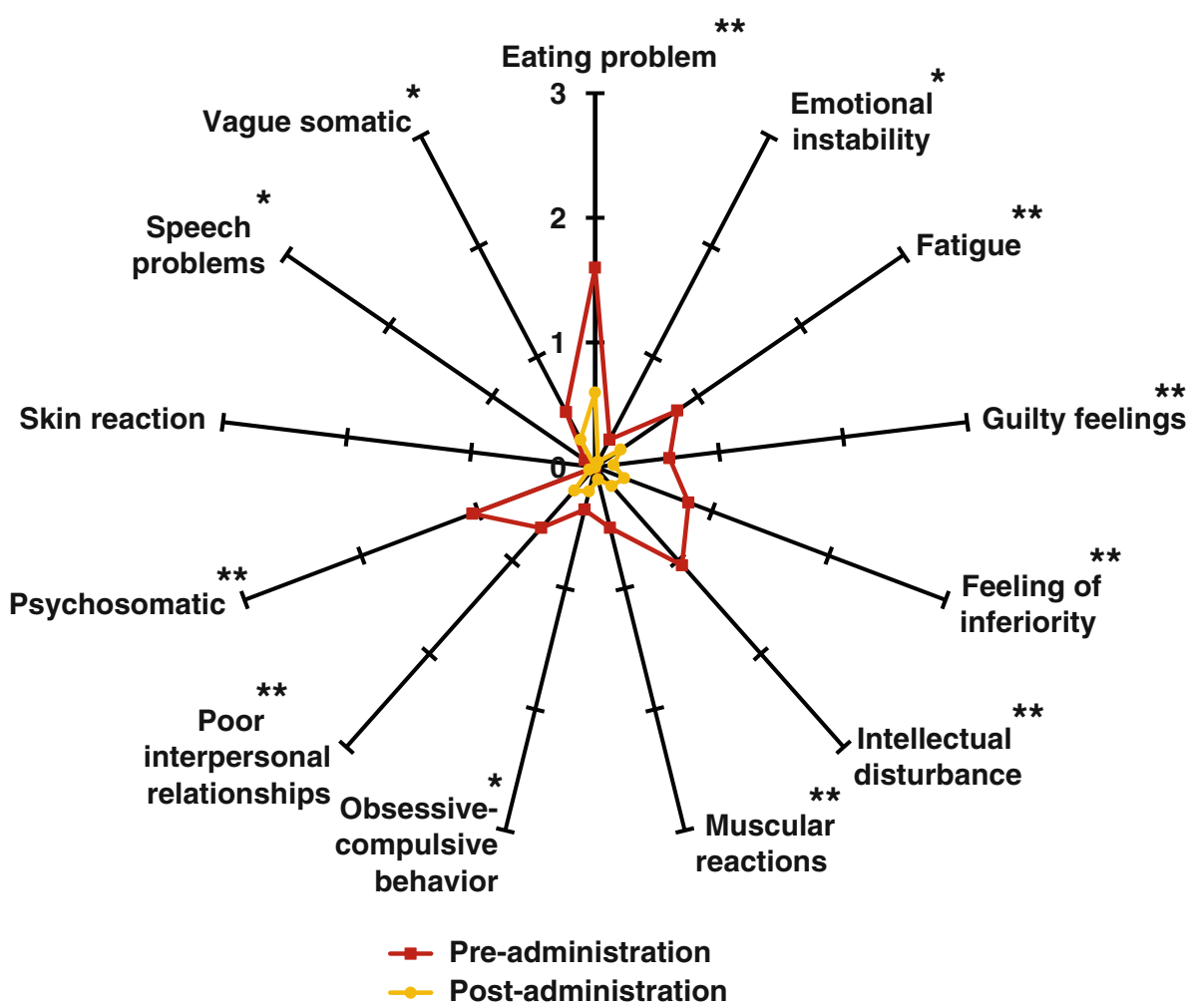

Table 3 Outcome of treatment with $\operatorname{Cyracos}^{\circledR}$ at endpoint using the CGI-I scale for determination of clinical improvement of anxiety and insomnia symptoms

\begin{tabular}{lrrrrr}
\hline Outcome & \multicolumn{2}{c}{ Anxiety } & & \multicolumn{2}{c}{ Insomnia } \\
\cline { 2 - 3 } & $n$ & & & $n$ & $\%$ \\
\hline Responder & 19 & 95 & & 20 & 100 \\
Nonresponder & 1 & 5 & & 0 \\
Very much improved & 14 & 70 & & 17 & 85 \\
Much improved & 5 & 25 & & 0 \\
Minimally improved & 1 & 5 & & 0 & 0 \\
No change & 0 & 0 & & 0 \\
Minimally worse & 0 & 0 & & 0 \\
Much worse & 0 & 0 & & 0 \\
Very much worse & 0 & 0 & 0 & 0 \\
\hline
\end{tabular}

Fig. 3 Insomnia parameters before and after 15 days of treatment with $600 \mathrm{mg}$ Cyracos $^{\circledR}$ (300 mg twice a day) in 20 volunteers affected by anxiety disorders and sleep disturbances. $* * p<0.01$

behavioral changes [1]. The reactions of individuals to anxiety are governed primarily by the limbic system of the brain. At this level, the amygdala is the area that is associated with the assignment of emotions, especially anxiety [26].

Physiologically, the amygdala manages the primary inputs of the nucleus accumbens, which comprises primarily medium spiny neurons that are special types of

inhibitory cells $[27,28]$. The neurotransmitter that is produced by these neurons is GABA [29]. Thus, it appears that anxiety is modulated by GABA levels in the brain.

Accordingly, the GABAergic system is a logical and promising target of new strategies to prevent and treat anxiety and its associated symptoms, such as restlessness and insomnia. GABA activity is mediated through $\mathrm{GABA}_{\mathrm{A}}$ and $\mathrm{GABA}_{B}$ receptor-dependent inhibition of the CNS, and GABA catabolism relies on GABA transaminase (GABA-T) levels [30]. 
Kennedy et al. [16] first proposed that Melissa officinalis L. exerts its anxiolytic effect and modulates mood through the GABAergic system. Recently, this proposed mechanism was examined in a preliminary screen of traditional anxiolytic botanical extracts [19], wherein the aqueous extract of Melissa officinalis L. effected the greatest inhibition of GABA-T activity. In a separate study, the same group isolated and identified rosmarinic acid and the triterpenoids pentacyclic ursolic acid and oleanolic acid as potent inhibitors of GABA-T [20].

Because the increase in GABAergic neurotransmission has been associated with reductions in anxiety, its associated symptoms and insomnia, the behavioral study in this work was aimed at determining the anti-anxiety effects of Melissa officinalis L. extract, Cyracos ${ }^{\circledR}$. Our results demonstrate that chronic administration of Cyracos ${ }^{\circledR} 300 \mathrm{mg}$ twice daily for 15 days significantly improved the psychological status of male and female volunteers who were affected by mild-tomoderate anxiety disorders and sleep disturbances. Holistically, this amelioration represented a shift in the distressed volunteers from having mild-to-moderate feelings of irritation to a near total attenuation of manifestations, as evidenced by the disappearance of significant signs, such as anxiety, its symptoms and insomnia after 15 days of treatment. This was also highlighted with a huge rate of responders.

With regard to the modulation of the manifestations of anxiety, total anxiety manifestations in the volunteers decreased by $18 \%$ after 15 days of treatment compared to the baseline score. These positive effects, which contributed to the improvement of anxiety disorders, confirm results from a recent study in which mice that were administered Cyracos ${ }^{\circledR}$ for 15 days improved their behavior significantly under moderate stress conditions [18]. The authors proposed a mechanism of action through the GABAergic pathway, involving inhibition of GABA-T and leading to an increase in GABA availability in the brain. The phytochemicals that were implicated in this proposed mechanism were rosmarinic acid and the triterpenoid pentacyclic acids, ursolic and oleanolic, as previously reported $[18,20]$.

At the appropriate dose, Cyracos $^{\circledR}$ inhibits GABA-T activity and therefore has anxiolytic-like effects $[18,20]$, whereas at too high a dose, it contributes significantly to increased anxiety and negative mood, as demonstrated in a study of rosmarinic acid on the behavior of mice under stressful conditions [31] and in a clinical trial on the anxiolytic effects of Melissa officinalis L. throughout induced stress [17].

With regard to overall anxiety-associated symptoms, Cyracos ${ }^{\circledR}$ treatment resulted in a significant improvement after 15 days, decreasing symptoms by $15 \%$ compared with baseline score. Notably, emotional instability, intellectual disturbances, and psychosomatic symptoms and speech problems improved.
These results constitute novel findings in a prospective observational chronic human trial, complementing a previous study on the attenuation of induced stress after acute administration of Melissa officinalis L. extract [16]. In this prior study, the authors suggested that the botanical improved stress-induced adverse effects and increased the speed of mathematical processing, which was linked easily to a decrease in intellectual disturbances, similar to our observations. Moreover, such manifestations were also reported to correlate closely with the many physical symptoms that develop in anxiety-affected subjects [32].

The positive effects of Melissa officinalis L. leaf extract in the present study on fatigue, muscular reactions and improvement in vague somatic symptoms can be connected to the antinociceptive properties of Melissa officinalis L. extract and rosmarinic acid, as demonstrated in a chemically induced nociception animal model [33]. In addition to these findings, Singh eliminated the possibility of any organic-based link in these volunteers and recommended that the presence of acute psychosocial stressors during anxiety should be studied more thoroughly [32].

We performed such an examination with the modified FRSA in this study. Notably, the decrease in anxiety manifestations was associated with a significant decline in the primary psychosocial symptoms after 15 days of treatment, as demonstrated by significant decrease in eating problems, feelings of guilt and inferiority, obsessivecompulsive behavior and poor interpersonal relationships.

These measures have been reported to be governed by a mechanism that involves the HPA axis [34], in which inhibition is thought to be mediated by GABA levels [35]. Consequently, whereas a small increase in GABAergic activity due to chronic Melissa officinalis L. extract intake might be sufficient to reduce moderate anxiety levels significantly, it might be ineffective during more stressful situations, depending on relative stress-induced HPA axis responses.

This open-label prospective study demonstrated that there was a significant improvement in insomnia after 15 days of treatment, which decreased by $42 \%$ compared with the baseline score. Amelioration of initial, middle, and delayed insomnia was observed, with volunteers showing improvement from having moderate levels of difficulties with falling asleep and restless nights to a level in which they were unaffected, corresponding to nights with no difficulties and full rest. Although it was not significant before the study, the rate of awakening also decreased after 15 days of treatment.

These results confirm previous reports that have suggested that $600 \mathrm{mg}$ of Melissa officinalis L. leaf extract per day is the appropriate dose to improve sleep parameters in healthy volunteers [36]. These findings are also consistent with the German Commission E recommendations regarding the 
approval of Melissa officinalis L. extract use for nervous insomnia [37]. However, although Cyracos ${ }^{\circledR}$ led to symptom improvement, the 15-day duration and the small sample size did not address the long-term efficacy and limited the interpretation of the significance of the study findings. It is possible that contact with the clinician contributed to part of the symptom improvement observed. Testing Cyracos $^{\circledR}$ in a larger sample using placebo-controlled designs and a longer time period will be critical to prove its effectiveness. Nevertheless, our study demonstrates that $600 \mathrm{mg}$ Cyracos ${ }^{\circledR}$, administrated in two daily doses for 15 days, is safe.

\section{Conclusion}

The present open-label prospective study investigated the effects of Cyracos $^{\circledR}$ administration; innovative results provide some evidence that the treatment might be beneficial to humans affected by mild-to-moderate anxiety disorders and sleep disturbance. For the first time, chronic Melissa officinalis L. leaf extract treatment has been demonstrated to improve mild-to-moderate anxiety disorders, its associated symptoms and insomnia in humans. Future studies, however, must incorporate a placebo arm, extend the number of subjects and examine the physiological stress markers of the HPA axis to verify the proposed mechanism of regulation by Melissa officinalis L. leaf extract through the GABAergic pathway. The extent to which its therapeutic effects depend on the availability and amounts of various constituents in the extract is unknown; nevertheless, many studies have reported rosmarinic acid and pentacyclic triterpenoid acids to mediate these effects through GABA metabolism [20].

Based on a psychosocial approach, these results and those from a previous work by Ibarra et al. [18] suggest a robust effect of Cyracos ${ }^{\circledR}$ on anxiety and insomnia. Moreover, the absence of sedatives and significant side effects render Cyracos ${ }^{\circledR}$ a viable option for mild-to-moderate anxiety disorder subjects. Therefore, they can avoid drugs, such as benzodiazepines, barbiturates and antidepressants, the use of which has been discouraged due to their soporific effects and other serious side effects, including acquired tolerance.

Acknowledgments The financial assistance from Naturex is gratefully acknowledged.

\section{Conflict of interest None.}

Open Access This article is distributed under the terms of the Creative Commons Attribution Noncommercial License which permits any noncommercial use, distribution, and reproduction in any medium, provided the original author(s) and source are credited.

\section{References}

1. Young EA, Liberzon I (2002) Stress and anxiety disorders. In: Donald WP, Arthur PA, Fahrbach SE, Anne ME, Robert TR (eds) Hormones. Brain and behavior. Academic Press, San Diego, pp 443-465

2. Beck AT, Steer RA (1991) Relationship between the Beck Anxiety Inventory and the Hamilton Anxiety Rating Scale with anxious outvolunteers. J Anxiety Disord 5:213-223

3. Ito A, Kikusui T, Takeuchi Y, Mori Y (2006) Effects of early weaning on anxiety and autonomic responses to stress in rats. Behav Brain Res 171:87-93

4. Vgontzas AN, Tsigos C, Bixler EO, Stratakis CA, Zachman K, Kales A, Vela-Bueno A, Chrousos GP (1998) Chronic insomnia and activity of the stress system: a preliminary study. J Psychosom Res 45:21-31

5. World Health Organization (1992) The ICD-10 classification of mental and behavioral disorders. http://www.who.int/substance abuse/terminology/icd_10/en/index.html. Accessed 23 November 2010

6. Larzelere MM, Wiseman P (2002) Anxiety, depression, and insomnia. Prim Care 29:339-360

7. Busto U, Sellers EM (1991) Pharmacologic aspects of benzodiazepine tolerance and dependence. J Subst Abuse Treat 8:29-33

8. Kavan MG, Elsasser G, Barone EJ (2009) Generalized anxiety disorder: practical assessment and management. Am Fam Physician 79:785-791

9. Head KA, Kelly GS (2009) Nutrients and botanicals for treatment of stress: adrenal fatigue, neurotransmitter imbalance, anxiety, and restless sleep. Altern Med Rev 14:114-140

10. Vorbach EU (1996) Therapie von insomnien: wirksamkeit und vertraglichkeit eines Baldrianpraparats. Psychopharmakotherapie 3:109-115

11. Bourin M, Bougerol T, Guitton B, Broutin E (1997) A combination of plant extracts in the treatment of outpatients with adjustment disorder with anxious mood: controlled study versus placebo. Fundam Clin Pharmacol 11:127-132

12. Viola H, Wolfman C, Levi SM, Wasowski C, Pena C, Medina JH, Paladini AC (1994) Isolation of pharmacologically active benzodiazepine receptor ligands from Tilia tomentosa (Tiliaceae). J Ethnopharmacol 44:47-53

13. European pharmacopeia (2005) Melissa officinalis L. monograph, vol 2, 5th edn. European pharmacopeia

14. Kennedy DO, Scholey AB, Tildesley NT, Perry EK, Wesnes KA (2002) Modulation of mood and cognitive performance following acute administration of Melissa officinalis (lemon balm). Pharmacol Biochem Behav 72:953-964

15. Kennedy DO, Wake G, Savelev S, Tildesley NT, Perry EK, Wesnes KA, Scholey AB (2003) Modulation of mood and cognitive performance following acute administration of single doses of Melissa officinalis (Lemon balm) with human CNS nicotinic and muscarinic receptor-binding properties. Neuropsychopharmacology 28:1871-1881

16. Kennedy DO, Little W, Scholey AB (2004) Attenuation of laboratory-induced stress in humans after acute administration of Melissa officinalis (Lemon Balm). Psychosom Med 66:607-613

17. Kennedy DO, Little W, Haskell CF, Scholey AB (2006) Anxiolytic effects of a combination of Melissa officinalis and Valeriana officinalis during laboratory induced stress. Phytother Res 20:96-102

18. Ibarra A, Feuillere N, Roller M, Lesburgere E, Beracochea D (2010) Effects of chronic administration of Melissa officinalis L. extract on anxiety-like reactivity and on circadian and exploratory activities in mice. Phytomedicine 17:397-403 
19. Awad R, Levac D, Cybulska P, Merali Z, Trudeau VL, Arnason JT (2007) Effects of traditionally used anxiolytic botanicals on enzymes of the gamma-aminobutyric acid (GABA) system. Can J Physiol Pharmacol 85:933-942

20. Awad R, Muhammad A, Durst T, Trudeau VL, Arnason JT (2009) Bioassay-guided fractionation of lemon balm (Melissa officinalis L.) using an in vitro measure of GABA transaminase activity. Phytother Res 23:1075-1081

21. American Psychiatric Association (1994) Diagnostic and statistical manual of mental disorders (DSM-IV), 4th edn. APA, Washington, DC

22. Carnat AP, Carnat A, Fraisse D, Lamaison JL (1998) The aromatic and polyphenolic composition of lemon balm (Melissa officinalis L. subsp. officinalis) tea. Pharm Acta Helv 72:301-305

23. Free SM Jr, Guthrie MB (1969) A new rating scale for evaluating clinical response in psychoneurotic outpatients. J Clin Pharmacol J New Drugs 9:187-194

24. Hamilton M (1960) A rating scale for depression. J Neurol Neurosurg Psychiatr 23:56-62

25. Guy W (1976) Assessment manual for psychopharmacology. National Institute of Mental Health, Rockville

26. Dickie EW, Armony JL (2008) Amygdala responses to unattended fearful faces: interaction between sex and trait anxiety. Psychiatry Res 162:51-57

27. Chi YY, Mogenson GJ (1982) Response of nucleus accumbens neurons to amygdala stimulation and its modification by dopamine. Brain Res 239:401-415

28. Johnson LR, Aylward RLM, Hussain Z, Totterdell S (1994) Input from the amygdala to the rat nucleus accumbens: its relationship with tyrosine hydroxylase immunoreactivity and identified neurons. Neuroscience 61:851-865

29. Kaufmann WA, Humpel C, Alheid GF, Marksteiner J (2003) Compartmentation of alpha 1 and alpha 2 GABAA receptor subunits within rat extended amygdala: implications for benzodiazepine action. Brain Res 964:91-99

30. Schousboe A, Waagepetersen HS (2009) Gamma-aminobutyric acid (GABA). In: Larry RS (ed) Encyclopedia of neuroscience. Academic Press, Oxford, pp 511-515

31. Pereira P, Tysca D, Oliveira P, da Silva Brum LF, Picada JN, Ardenghi P (2005) Neurobehavioral and genotoxic aspects of rosmarinic acid. Pharmacol Res 52:199-203

32. Singh AN (2006) Recent advances in the psychopharmacology of psychosomatic medicine. Int Congr Ser 1287:206-212

33. Guginski G, Luiz AP, Silva MD, Massaro M, Martins MF, Chaves J, Mattos RW, Silveira D, Ferreira VMM, Calixto JB,
Santos ARS (2009) Mechanisms involved in the antinociception caused by ethanolic extract obtained from the leaves of Melissa officinalis (lemon balm) in mice. Pharmacol Biochem Behav 93:10-16

34. Foley P, Kirschbaum C (2010) Human hypothalamus-pituitaryadrenal axis responses to acute psychosocial stress in laboratory settings. Neurosci Biobehav Rev 35:91-96

35. Cullinan W, Ziegler D, Herman J (2008) Functional role of local GABAergic influences on the HPA axis. Brain Struct Funct 213:63-72

36. Wheatley D (2005) Medicinal plants for insomnia: a review of their pharmacology, efficacy and tolerability. J Psychopharmacol 19:414-421

37. Blumenthal M, Goldberg A, Brinckman J (2000) Expanded commission E monographs. American Botanical Council, Austin

38. Dastmalchi K, Damien Dorman HJ, Oinonen PP, Darwis Y, Laakso I, Hiltunen R (2008) Chemical composition and in vitro antioxidative activity of a lemon balm (Melissa officinalis L.) extract. Lebenson Wiss Technol 41:391-400

39. Caniova A, Brandsteterova E (2001) HPLC analysis of phenolic acids in Melissa officinalis. J Liq Chrom Rel Technol 24: 2647-2659

40. Kim S, Yun EJ, Bak JS, Lee H, Lee SJ, Kim CT, Lee JH, Kim KH (2010) Response surface optimised extraction and chromatographic purification of rosmarinic acid from Melissa officinalis leaves. Food Chem 121:521-526

41. Fecka I, Turek S (2007) Determination of water-soluble polyphenolic compounds in commercial herbal teas from Lamiaceae: peppermint, melissa, and sage. J Agric Food Chem 55: 10908-10917

42. Hohmann J, Zupko I, Redei D, Csanyi M, Falkay G, Mathe I, Janicsak G (1999) Protective effects of the aerial parts of Salvia officinalis, Melissa Officinalis and Lavandula angustifolia and their constituents against enzyme-dependent and enzyme-independent lipid peroxidation. Planta Med 65:576-578

43. Bouayed J, Piri K, Rammal H, Dicko A, Desor F, Younos C, Soulimani R (2007) Comparative evaluation of the antioxidant potential of some Iranian medicinal plants. Food Chem 104: 364-368

44. Herodez SS, Hadolin M, Skerget M, Kne Z (2003) Solvent extraction study of antioxidants from Balm (Melissa officinalis L.) leaves. Food Chem 80:275-282

45. Janicsak G, Veres K, Zoltan Kakasy A, Mathe I (2006) Study of the oleanolic and ursolic acid contents of some species of the Lamiaceae. Biochem Syst Ecol 34:392-396 